\title{
On the Locating Chromatic Number of Certain Barbell Graphs
}

\author{
Asmiati $\mathbb{D}^{1},{ }^{1}$ I. Ketut Sadha Gunce Yana, ${ }^{1}$ and Lyra Yulianti ${ }^{2}$ \\ ${ }^{1}$ Mathematics Department, Faculty of Mathematics and Natural Sciences, Lampung University, \\ Jl. Brodjonegoro No.1 Bandar Lampung, Indonesia \\ ${ }^{2}$ Mathematics Department, Faculty of Mathematics and Natural Sciences, Andalas University, \\ Kampus UNAND Limau Manis, Padang 25163, Indonesia \\ Correspondence should be addressed to Asmiati; asmiati308@yahoo.com
}

Received 27 March 2018; Revised 26 June 2018; Accepted 22 July 2018; Published 5 August 2018

Academic Editor: Dalibor Froncek

Copyright (C) 2018 Asmiati et al. This is an open access article distributed under the Creative Commons Attribution License, which permits unrestricted use, distribution, and reproduction in any medium, provided the original work is properly cited.

\begin{abstract}
The locating chromatic number of a graph $G$ is defined as the cardinality of a minimum resolving partition of the vertex set $V(G)$ such that all vertices have distinct coordinates with respect to this partition and every two adjacent vertices in $G$ are not contained in the same partition class. In this case, the coordinate of a vertex $v$ in $G$ is expressed in terms of the distances of $v$ to all partition classes. This concept is a special case of the graph partition dimension notion. In this paper we investigate the locating chromatic number for two families of barbell graphs.
\end{abstract}

\section{Introduction}

The partition dimension was introduced by Chartrand et al. [1] as the development of the concept of metric dimension. The application of metric dimension plays a role in robotic navigation [2], the optimization of threat detecting sensors [3], and chemical data classification [4]. The concept of locating chromatic number is a marriage between the partition dimension and coloring of a graph, first introduced by Chartrand et al in 2002 [5]. The locating chromatic number of a graph is a newly interesting topic to study because there is no general theorem for determining the locating chromatic number of any graph.

Let $G=(V, E)$ be a connected graph. We define the distance as the minimum length of path connecting vertices $u$ and $v$ in $G$, denoted by $d(u, v)$. A $k$-coloring of $G$ is a function $c: V(G) \longrightarrow\{1,2, \ldots, k\}$, where $c(u) \neq c(v)$ for any two adjacent vertices $u$ and $v$ in $G$. Thus, the coloring $c$ induces a partition $\Pi$ of $V(G)$ into $k$ color classes (independent sets) $C_{1}, C_{2}, \ldots, C_{k}$, where $C_{i}$ is the set of all vertices colored by the color $i$ for $1 \leq i \leq k$. The color code $c_{\Pi}(v)$ of a vertex $v$ in $G$ is defined as the $k$-vector $\left(d\left(v, C_{1}\right), d\left(v, C_{2}\right), \ldots, d\left(v, C_{k}\right)\right)$, where $d\left(v, C_{i}\right)=\min \left\{d(v, x): x \in C_{i}\right\}$ for $1 \leq i \leq k$. The $k$-coloring $c$ of $G$ such that all vertices have different color codes is called a locating coloring of $G$. The locating chromatic number of $G$, denoted by $\chi_{L}(G)$, is the minimum $k$ such that $G$ has a locating coloring.

The following theorem is a basic theorem proved by Chartrand et al. [5]. The neighborhood of vertex $u$ in a connected graph $G$, denoted by $N(u)$, is the set of vertices adjacent to $u$.

Theorem 1 (see [5]). Let c be a locating coloring in a connected graph $G$. If $u$ and $v$ are distinct vertices of $G$ such that $d(u, t)=$ $d(v, t)$ for all $t \in V(G)-\{u, v\}$, then $c(u) \neq c(v)$. In particular, if $u$ and $v$ are non-adjacent vertices of $G$ such that $N(u)=N(v)$, then $c(u) \neq c(v)$.

The following corollary gives the lower bound of the locating chromatic number for every connected graph $G$.

Corollary 2 (see [5]). If $G$ is a connected graph and there is a vertex adjacent to $k$ leaves, then $\chi_{L}(G) \geq k+1$.

There are some interesting results related to the determination of the locating chromatic number of some graphs. The results are obtained by focusing on certain families of graphs. Chartrand et al. in [5] have determined all graphs of order $n$ with locating chromatic number $n$, namely, a complete multipartite graph of $n$ vertices. Moreover, Chartrand et 
al. [6] have succeeded in constructing tree on $n$ vertices, $n \geq 5$, with locating chromatic numbers varying from 3 to $n$, except for $(n-1)$. Then Behtoei and Omoomi [7] have obtained the locating chromatic number of the Kneser graphs. Recently, Asmiati et al. [8] obtained the locating chromatic number of the generalized Petersen graph $P(n, 1)$ for $n \geq 3$. Baskoro and Asmiati [9] have characterized all trees with locating chromatic number 3. In [10] all trees of order $n$ with locating chromatic number $n-1$ were characterized, for any integers $n$ and $t$, where $n>t+3$ and $2 \leq t<n / 2$. Asmiati et al. in [11] have succeeded in determining the locating chromatic number of homogeneous amalgamation of stars and their monotonicity properties and in [12] for firecracker graphs. Next, Wellyyanti et al. [13] determined the locating chromatic number for complete $n$ ary trees.

The generalized Petersen graph $P(n, m), n \geq 3$ and $1 \leq$ $m \leq\lfloor(n-1) / 2\rfloor$, consists of an outer $n$-cycle $y_{1}, y_{2}, \ldots, y_{n}$, a set of $n$ spokes $y_{i} x_{i}, 1 \leq i \leq n$, and $n$ edges $x_{i} x_{i+m}$, $1 \leq i \leq n$, with indices taken modulo $n$. The generalized Petersen graph was introduced by Watkins in [14]. Let us note that the generalized Petersen graph $P(n, 1)$ is a prism defined as Cartesian product of a cycle $C_{n}$ and a path $P_{2}$.

Next theorems give the locating chromatic numbers for complete graph $K_{n}$ and generalized Petersen graph $P(n, 1)$.

Theorem 3 (see [6]). For $n \geq 2$, the locating chromatic number of complete graph $K_{n}$ is $n$.

Theorem 4 (see [8]). The locating chromatic number of generalized Petersen graph $P(n, 1)$ is 4 for odd $n \geq 3$ or 5 for even $n \geq 4$.

The barbell graph is constructed by connecting two arbitrary connected graphs $G$ and $H$ by a bridge. In this paper, firstly we discuss the locating chromatic number for barbell graph $B_{m, n}$ for $m, n \geq 3$, where $G$ and $H$ are complete graphs on $m$ and $n$ vertices, respectively. Secondly, we determine the locating chromatic number of barbell graph $B_{P(n, 1)}$ for $n \geq 3$, where $G$ and $H$ are two isomorphic copies of the generalized Petersen graph $P(n, 1)$.

\section{Results and Discussion}

Next theorem proves the exact value of the locating chromatic number for barbell graph $B_{n, n}$.

Theorem 5. Let $B_{n, n}$ be a barbell graph for $n \geq 3$. Then the locating chromatic number of $B_{n, n}$ is $\chi_{L}\left(B_{n, n}\right)=n+1$.

Proof. Let $B_{n, n}, n \geq 3$, be the barbell graph with the vertex set $V\left(B_{n, n}\right)=\left\{u_{i}, v_{i}: 1 \leq i \leq n\right\}$ and the edge set $E\left(B_{n, n}\right)$ $=\bigcup_{i=1}^{n-1}\left\{u_{i} u_{i+j}: 1 \leq j \leq n-i\right\} \cup \bigcup_{i=1}^{n-1}\left\{v_{i} v_{i+j}: 1 \leq j \leq\right.$ $n-i\} \cup\left\{u_{n} v_{n}\right\}$.

First, we determine the lower bound of the locating chromatic number for barbell graph $B_{n, n}$ for $n \geq 3$. Since the barbell graph $B_{n, n}$ contains two isomorphic copies of a complete graph $K_{n}$, then with respect to Theorem 3 we have $\chi_{L}\left(B_{n, n}\right) \geq n$. Next, suppose that $c$ is a locating coloring using $n$ colors. It is easy to see that the barbell graph $B_{n, n}$ contains two vertices with the same color codes, which is a contradiction. Thus, we have that $\chi_{L}\left(B_{n, n}\right) \geq n+1$.

To show that $n+1$ is an upper bound for the locating chromatic number of barbell graph $B_{n, n}$ it suffices to prove the existence of an optimal locating coloring $c: V\left(B_{n, n}\right) \longrightarrow$ $\{1,2, \ldots, n+1\}$. For $n \geq 3$ we construct the function $c$ in the following way:

$$
\begin{aligned}
& c\left(u_{i}\right)=i, \quad 1 \leq i \leq n \\
& c\left(v_{i}\right)= \begin{cases}n, & \text { for } i=1 \\
i, & \text { for } 2 \leq i \leq n-1 \\
n+1, & \text { otherwise. }\end{cases}
\end{aligned}
$$

By using the coloring $c$, we obtain the color codes of $V\left(B_{n, n}\right)$ as follows:

$$
\begin{aligned}
& c_{\Pi}\left(u_{i}\right) \\
& = \begin{cases}0, & \text { for } i^{t h} \text { component, } 1 \leq i \leq n \\
2, & \text { for }(n+1)^{t h} \text { component, } 1 \leq i \leq n-1 \\
1, & \text { otherwise, }\end{cases} \\
& c_{\Pi}\left(v_{i}\right)= \begin{cases}0, & \text { for } i^{t h} \text { component, } 2 \leq i \leq n-1 \\
\text { for } n^{t h} \text { component, } i=1, \text { and } \\
3, & \text { for } 1^{\text {st }} \text { component, } 1 \leq i \leq n-1 \\
2, & \text { for } 1^{\text {st }} \text { component, } i=n \\
1, & \text { otherwise. }\end{cases}
\end{aligned}
$$

Since all vertices in $V\left(B_{n, n}\right)$ have distinct color codes, then the coloring $c$ is desired locating coloring. Thus, $\chi_{L}\left(B_{n, n}\right)=$ $n+1$.

Corollary 6. For $n, m \geq 3$, and $m \neq n$, the locating chromatic number of barbell graph $B_{m, n}$ is

$$
\chi_{L}\left(B_{m, n}\right)=\max \{m, n\}
$$

Next theorem provides the exact value of the locating chromatic number for barbell graph $B_{P(n, 1)}$.

Theorem 7. Let $B_{P(n, 1)}$ be a barbell graph for $n \geq 3$. Then the locating chromatic number of $B_{P(n, 1)}$ is 


$$
\chi_{L}\left(B_{P(n, 1)}\right)= \begin{cases}4, & \text { for odd } n \\ 5, & \text { for even } n\end{cases}
$$

Proof. Let $B_{P(n, 1)}, n \geq 3$, be the barbell graph with the vertex set $V\left(B_{P(n, 1)}\right)=\left\{u_{i}, u_{n+i}, w_{i}, w_{n+i}: 1 \leq i \leq n\right\}$ and the edge set $E\left(B_{P(n, 1)}\right)=\left\{u_{i} u_{i+1}, u_{n+i} u_{n+i+1}, w_{i} w_{i+1}, w_{n+i} w_{n+i+1}: 1 \leq i \leq\right.$ $n-1\} \cup\left\{u_{n} u_{1}, u_{2 n} u_{n+1}, w_{n} w_{1}, w_{2 n} w_{n+1}\right\} \cup\left\{u_{i} u_{n+i}, w_{i} w_{n+i}: 1 \leq\right.$ $i \leq n\} \cup\left\{u_{n} w_{n}\right\}$.

Let us distinguish two cases.

Case 1 ( $n$ odd). According to Theorem 4 for $n$ odd we have $\chi_{L}\left(B_{P(n, 1)}\right) \geq 4$. To show that 4 is an upper bound for the locating chromatic number of the barbell graph $B_{P(n, 1)}$ we describe an locating coloring $c$ using 4 colors as follows:

$$
\begin{gathered}
c\left(u_{i}\right)= \begin{cases}1, & \text { for } i=1 \\
3, & \text { for even } i, i \geq 2 \\
4, & \text { for odd } i, i \geq 3 .\end{cases} \\
c\left(u_{n+i}\right)= \begin{cases}2, & \text { for } i=1 \\
3, & \text { for odd } i, i \geq 3 \\
4, & \text { for even } i, i \geq 2 .\end{cases} \\
c\left(w_{i}\right)= \begin{cases}1, & \text { for odd } i, i \leq n-2 \\
2, & \text { for even } i, i \leq n-1 \\
3, & \text { for } i=n .\end{cases} \\
c\left(w_{n+i}\right)= \begin{cases}1, & \text { for even } i, i \leq n-1 \\
2, & \text { for odd } i, i \leq n-2 \\
4, & \text { for } i=n .\end{cases}
\end{gathered}
$$

For $n$ odd the color codes of $V\left(B_{P(n, 1)}\right)$ are

$$
\begin{aligned}
& c_{\Pi}\left(u_{i}\right) \\
& = \begin{cases}i, & \text { for } 2^{n d} \text { component, } i \leq \frac{n+1}{2} \\
i-1, & \text { for } 1^{\text {st }} \text { component, } i \leq \frac{n+1}{2} \\
n-i+1, & \text { for } 1^{\text {st }} \text { component, } i>\frac{n+1}{2} \\
n-i+2, & \text { for } 2^{n d} \text { component, } i>\frac{n+1}{2} \\
0, & \text { for } 3^{\text {th }} \text { component, } i \text { even, } i \geq 2 \\
1, & \text { for } 4^{\text {th }} \text { component, } i \text { odd, } i \geq 3 \\
\text { otherwise. }\end{cases}
\end{aligned}
$$

$$
\begin{aligned}
& \mathcal{c}_{\Pi}\left(u_{n+i}\right) \\
& = \begin{cases}i, & \text { for } 1^{\text {st }} \text { component, } i \leq \frac{n+1}{2} \\
i-1, & \text { for } 2^{\text {nd }} \text { component, } i \leq \frac{n+1}{2} \\
n-i+1, & \text { for } 2^{\text {nd }} \text { component, } i>\frac{n+1}{2} \\
n-i+2, & \text { for } 1^{\text {st }} \text { component, } i>\frac{n+1}{2} \\
0, & \text { for } 4^{\text {th }} \text { component, } i \text { even, } i \geq 2 \\
1, & \text { for } 3^{\text {th }} \text { component, } i \text { odd, } i \geq 3\end{cases}
\end{aligned}
$$$$
c_{\Pi}\left(w_{i}\right)
$$$$
i, \quad \text { for } 3^{\text {th }} \text { component, } i \leq \frac{n-1}{2}
$$$$
i+1, \quad \text { for } 4^{\text {th }} \text { component, } i \leq \frac{n-1}{2}
$$$$
= \begin{cases}n-i, & \text { for } 3^{\text {th }} \text { component, } i \geq \frac{n+1}{2} \\ n-i+1, & \text { for } 4^{\text {th }} \text { component, } i \geq \frac{n+1}{2}\end{cases}
$$$$
\text { 0, for } 2^{\text {nd }} \text { component, } i \text { even, } i \leq n-1
$$$$
\text { for } 1^{\text {st }} \text { component, } i \text { odd, } i \leq n-2
$$$$
\text { 1, otherwise. }
$$$$
c_{\Pi}\left(w_{n+i}\right)
$$$$
= \begin{cases}i, & \text { for } 4^{\text {th }} \text { component, } i \leq \frac{n-1}{2} \\ i+1, & \text { for } 3^{\text {th }} \text { component, } i \leq \frac{n-1}{2} \\ n-i, & \text { for } 4^{\text {th }} \text { component, } i \geq \frac{n+1}{2} \\ n-i+1, & \text { for } 3^{\text {th }} \text { component, } i \geq \frac{n+1}{2} \\ 0, & \text { for } 1^{\text {st }} \text { component, } i \text { even, } i \leq n-1 \\ 1, & \text { for } 2^{n d} \text { component, } i \text { odd, } i \leq n-2 \\ & \text { otherwise. }\end{cases}
$$

Since all vertices in $B_{P(n, 1)}$ have distinct color codes, then the coloring $c$ with 4 colors is an optimal locating coloring and it proves that $\chi_{L}\left(B_{P(n, 1)}\right) \leq 4$.

Case 2 ( $n$ even). In view of the lower bound from Theorem 7 it suffices to prove the existence of a locating coloring $c$ : $V\left(B_{P(n, 1)}\right) \longrightarrow\{1,2, \ldots, 5\}$ such that all vertices in $B_{P(n, 1)}$ have distinct color codes. For $n$ even, $n \geq 4$, we describe the locating coloring in the following way:

$$
c\left(u_{i}\right)= \begin{cases}1, & \text { for } i=1 \\ 3, & \text { for even } i, 2 \leq i \leq n-2 \\ 4, & \text { for odd } i, 3 \leq i \leq n-1 \\ 5, & \text { for } i=n .\end{cases}
$$




$$
\begin{aligned}
& c\left(u_{n+i}\right)= \begin{cases}2, & \text { for } i=1 \\
3, & \text { for odd } i, i \geq 3 \\
4, & \text { for even } i, i \geq 2 .\end{cases} \\
& c\left(w_{i}\right)= \begin{cases}1, & \text { for odd } i, i \leq n-3 \\
2, & \text { for even } i, i \leq n-2 \\
3, & \text { for } i=n-1 \\
4, & \text { for } i=n .\end{cases} \\
& c\left(w_{n+i}\right)= \begin{cases}1, & \text { for even } i, i \leq n-2 \\
2, & \text { for odd } i, i \leq n-1 \\
5, & \text { for } i=n .\end{cases}
\end{aligned}
$$

In fact, our locating coloring of $B_{P(n, 1)}, n$ even, has been chosen in such a way that the color codes are

$$
\begin{aligned}
& c_{\Pi}\left(u_{i}\right) \\
& \begin{cases}i, & \text { for } 2^{\text {nd }} \text { and } 5^{\text {th }} \text { components, } i \leq \frac{n}{2} \\
i-1, & \text { for } 1^{\text {st }} \text { component, } i \leq \frac{n}{2} \\
n-i, & \text { for } 5^{\text {th }} \text { component, } i>\frac{n}{2} \\
n-i+1, & \text { for } 1^{\text {st }} \text { component, } i>\frac{n}{2} \\
n-i+2, & \text { for } 2^{\text {nd }} \text { component, } i>\frac{n}{2} \\
0, & \text { for } 3^{\text {th }} \text { component, } i \text { even, } 2 \leq i \leq n-2 \\
& \text { for } 4^{\text {th }} \text { component, } i \text { odd, } 3 \leq i \leq n-1 \\
2, & \text { for } 4^{\text {th }} \text { component, } i=1 \\
& \text { for } 3^{\text {th }} \text { component, } i=n \\
1, & \text { otherwise. }\end{cases} \\
& c_{\Pi}\left(u_{n+i}\right) \\
& \begin{cases}i, & \text { for } 1^{\text {st }} \text { component, } i \leq \frac{n}{2} \\
i-1, & \text { for } 2^{\text {nd }} \text { component, } i \leq \frac{n}{2} \\
n+i, & \text { for } 5^{\text {th }} \text { component, } i \leq \frac{n}{2} \\
n-i+1, & \text { for } 2^{\text {nd }} \text { and } 5^{\text {th }} \text { components, } i>\frac{n}{2} \\
n-i+2, & \text { for } 1^{\text {th }} \text { component, } i>\frac{n}{2} \\
0, & \text { for } 3^{\text {th }} \text { component, } i \text { odd, } 3 \leq i \leq n-1 \\
& \text { for } 4^{\text {th }} \text { component, } i \text { even, } 2 \leq i \leq n \\
2, & \text { for } 3^{\text {th }} \text { component, } i=1 \\
1, & \text { otherwise. }\end{cases}
\end{aligned}
$$

$$
\begin{aligned}
& c_{\Pi}\left(w_{i}\right) \\
& = \begin{cases}i, & \text { for } 4^{\text {th }} \text { component, } i \leq \frac{n}{2} \\
i+1, & \text { for } 5^{t h} \text { component, } i \leq \frac{n}{2} \\
& \text { for } 3^{\text {th }} \text { component, } i \leq \frac{n}{2}-1 \\
n-i, & \text { for } 4^{\text {th }} \text { component, } i>\frac{n}{2} \\
n-i+1, & \text { for } 5^{\text {th }} \text { component, } i>\frac{n}{2} \\
n-i-1, & \text { for } 3^{\text {th }} \text { component, } \frac{n}{2} \leq i \leq n-1 \\
0, & \text { for } 1^{\text {st }} \text { component, } i \text { odd, } i \leq n-3 \\
2, & \text { for } 2^{\text {nd }} \text { component, } i \text { even, } i \leq n-2 \\
& \text { for } 1^{\text {st }} \text { component, } i=n-1 \\
1, & \text { for } 2^{\text {nd }} \text { component, } i=n\end{cases}
\end{aligned}
$$$$
c_{\Pi}\left(w_{n+i}\right)
$$$$
\begin{cases}i, & \text { for } 5^{\text {th }} \text { component, } i \leq \frac{n}{2} \\ i+1, & \text { for } 4^{\text {th }} \text { component, } i \leq \frac{n}{2} \\ i+2 & \text { for } 3^{\text {th }} \text { component, } i \leq \frac{n}{2}-1 \\ n-i, & \text { for } 3^{\text {th }} \text { component, } \frac{n}{2} \leq i \leq n-1 \\ & \text { for } 5^{\text {th }} \text { component, } i>\frac{n}{2} \\ n-i+1, & \text { for } 4^{\text {th }} \text { component, } i>\frac{n}{2} \\ 0, & \text { for } 1^{\text {st }} \text { component, } i \text { even, } i \leq n-2 \\ 2, & \text { for } 2^{\text {nd }} \text { component, } i \text { odd, } i \leq n-1 \\ 1, & \text { for } 1^{\text {st }} \text { and } 3^{\text {th }} \text { components, } i=n\end{cases}
$$

Since for $n$ even all vertices of $B_{P(n, 1)}$ have distinct color codes then our locating coloring has the required properties and $\chi_{L}\left(B_{P(n, 1)}\right) \leq 5$. This concludes the proof.

\section{Data Availability}

The data used to support the findings of this study are available from the corresponding author upon request.

\section{Conflicts of Interest}

The authors declare that they have no conflicts of interest.

\section{Acknowledgments}

The authors are thankful to DRPM Dikti for the Fundamental Grant 2018. 


\section{References}

[1] G. Chartrand, P. Zhang, and E. Salehi, "On the partition dimension of a graph," Congressus Numerantium, vol. 130, pp. 157-168, 1998.

[2] V. Saenpholphat and P. Zhang, "Conditional resolvability: a survey," International Journal of Mathematics and Mathematical Sciences, vol. 38, pp. 1997-2017, 2004.

[3] M. Johnson, "Structure-activity maps for visualizing the graph variables arising in drug design," Journal of Biopharmaceutical Statistics, vol. 3, no. 2, pp. 203-236, 1993.

[4] G. Chartrand and P. Zhang, "THE theory and applications of resolvability in graphs. A survey," vol. 160, pp. 47-68.

[5] G. Chartrand, D. Erwin, M. A. Henning, P. J. Slater, and P. Zhang, "The locating-chromatic number of a graph," Bulletin of the Institute of Combinatorics and Its Applications, vol. 36, pp. 89-101, 2002.

[6] G. Chartrand, D. Erwin, M. A. Henning, P. J. Slater, and P. Zhang, "Graphs of order $n$-1," Discrete Mathematics, vol. 269, no. 1-3, pp. 65-79, 2003.

[7] A. Behtoei and B. Omoomi, "On the locating chromatic number of Kneser graphs," Discrete Applied Mathematics: The Journal of Combinatorial Algorithms, Informatics and Computational Sciences, vol. 159, no. 18, pp. 2214-2221, 2011.

[8] Asmiati, Wamiliana, Devriyadi, and L. Yulianti, "On some petersen graphs having locating chromatic number four or five," Far East Journal of Mathematical Sciences, vol. 102, no. 4, pp. 769-778, 2017.

[9] E. T. Baskoro and Asmiati, "Characterizing all trees with locating-chromatic number 3," Electronic Journal of Graph Theory and Applications. EJGTA, vol. 1, no. 2, pp. 109-117, 2013.

[10] D. K. Syofyan, E. T. Baskoro, and H. Assiyatun, "Trees with certain locating-chromatic number," Journal of Mathematical and Fundamental Sciences, vol. 48, no. 1, pp. 39-47, 2016.

[11] Asmiati, H. Assiyatun, and E. T. Baskoro, "Locating-chromatic number of amalgamation of stars," ITB Journal of Science, vol. 43A, no. 1, pp. 1-8, 2011.

[12] Asmiati, H. Assiyatun, E. T. Baskoro, D. Suprijanto, R. Simanjuntak, and S. Uttunggadewa, "The locating-chromatic number of firecracker graphs," Far East Journal of Mathematical Sciences (FJMS), vol. 63, no. 1, pp. 11-23, 2012.

[13] D. Welyyanti, E. T. Baskoro, R. Simanjuntak, and S. Uttunggadewa, "On locating-chromatic number of complete $n$-ary tree," AKCE International Journal of Graphs and Combinatorics, vol. 10, no. 3, pp. 309-315, 2013.

[14] M. E. Watkins, "A theorem on tait colorings with an application to the generalized Petersen graphs," Journal of Combinatorial Theory, vol. 6, no. 2, pp. 152-164, 1969. 


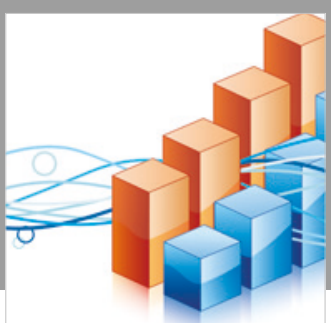

Advances in

Operations Research

\section{-n-m}
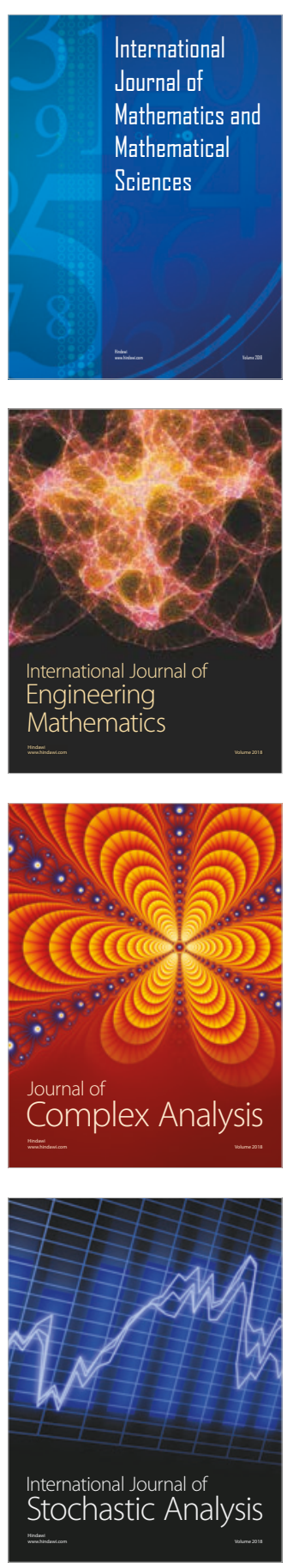
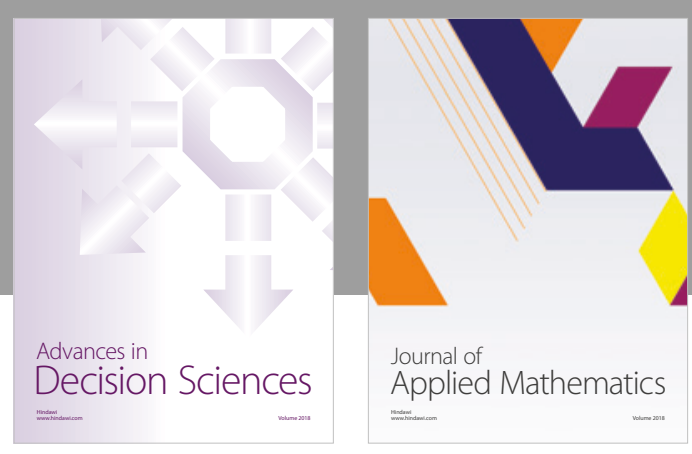

Journal of

Applied Mathematics
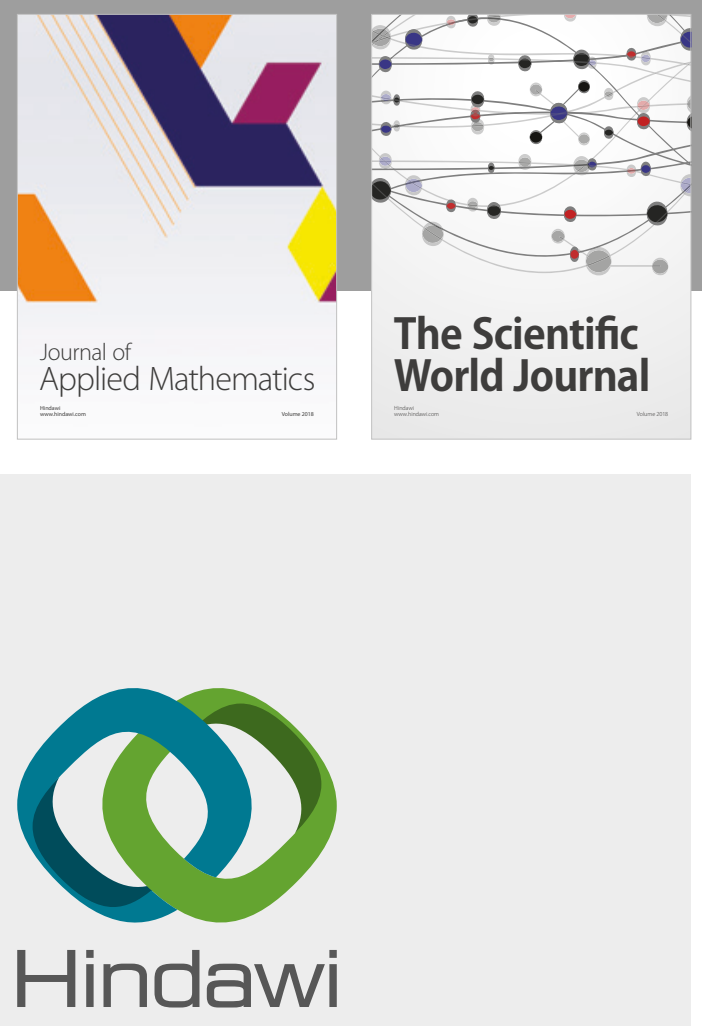

Submit your manuscripts at

www.hindawi.com

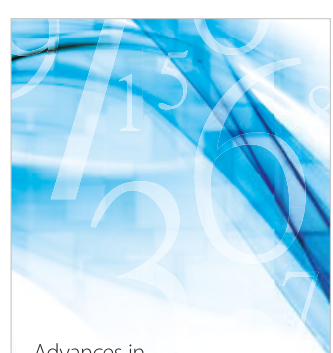

Advances in
Numerical Analysis
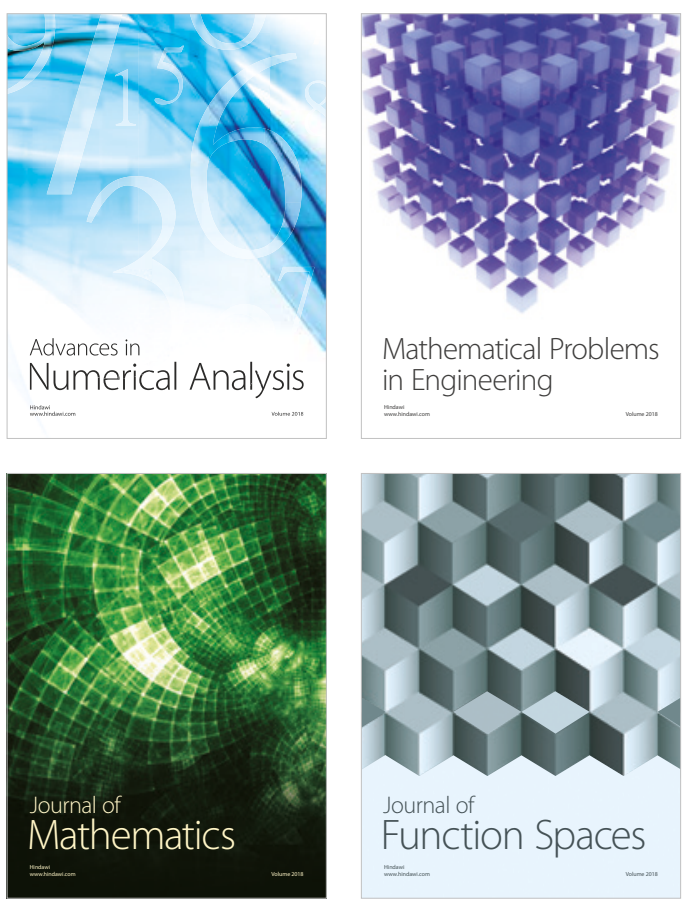

Mathematical Problems in Engineering

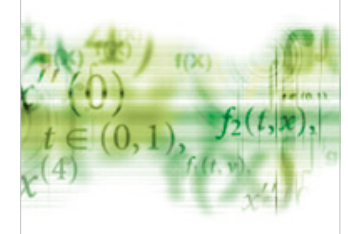

International Journal of

Differential Equations

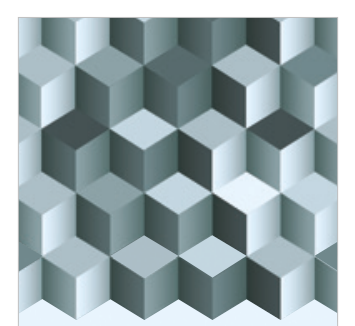

Journal of

Function Spaces

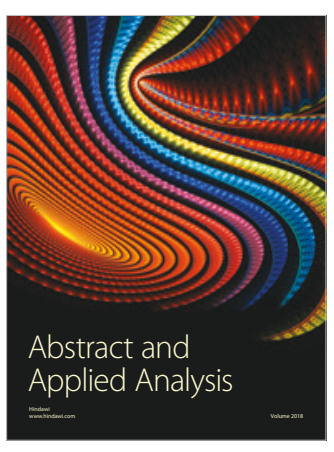

The Scientific

World Journal

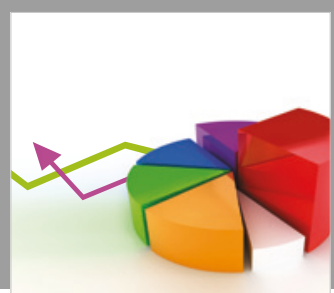

Journal of

Probability and Statistics
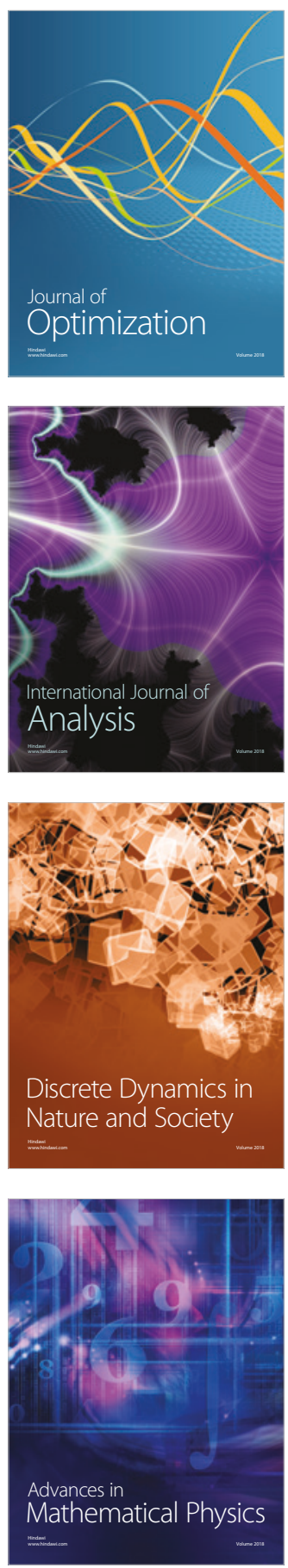